\title{
THE NUCLEAR PATTERN OF THE NON-TECTAL PORTIONS OF THE MIDBRAIN AND ISTHMUS IN THE SHREW AND THE BAT
}

\author{
ELIZABETH C. CROSBY AND RUSSELL T. WOODBURNE \\ Department of Anatomy, University of Michigan \\ TEN PLATES (SIXTEEN FIgURES)
}

\section{INTRODUCTION}

The admirable work by Castaldi ('23, '24, '26) on the midbrain of the guinea pig has laid an excellent foundation for the study of this region in the various mammalian forms. Previous to his time the general pattern of the area had been presented in the atlases of the cat and rabbit brain by Winkler and Potter ('11 and '14). Various regions of the mammalian midbrain have received special consideration in studies based on normal cell and fiber preparations and following experimental lesions or in connection with clinical syndromes. Yet for the bat and the shrew the finer details of nuclear pattern and fiber relations in the non-tectal portions of the midbrain are, for the most part, unknown. Ganser (1882), in an insectivore, the mole, identified a few of the mesencephalic centers and described in some detail the interpeduncular nucleus.

The material used for the present report belongs to the Huber Neurological Collection of the Department of Anatomy of the University of Michigan. In part it consists of transversely and sagittally cut series stained with toluidin blue which were prepared by the late Prof. G. Carl Huber. The rest of the series were made through technical assistance provided by a special grant from the Horace $H$. Rackham School of Graduate Studies of the University of Michigan, for which the writers wish to express their thanks. 
In both the shrew (Blarina brevicauda) and the bat (Tarida mexicana) there is a very considerable rostrocaudal compression of the brain (figs. 1, 16), as various observers have noted (Humphrey, '36; Gillilan, '41; and others). Consequently it is quite impossible to cut the brain of either form serially so that more than a small proportion of the sections are in a true transverse plane. Their oblique tilt in the series used is interpreted in the accompanying diagrams (figs. 1 and 16).

PART I. THE SHREW

\section{THE PERIVENTRICULAR GROUPS}

\section{General areas of periventricular gray}

Compared with that of many other forms, the periventricular or central gray of the shrew does not show so high a degree of differentiation, this lack being particularly marked in the rostral two-thirds of the area. Moreover, there is no sharp line of demarcation between the diencephalic and mesencephalic periventricular gray. The less densely arranged gray surrounding the ventricle of the caudoventral end of the diencephalon passes over into similarly arranged cells in the cephalic levels of the mesencephalon (fig. 2). These latter are gradually replaced by more densely grouped periventricular gray in planes which mark the overlap of the small- and large-celled portions of the red nucleus. At such red nuclear levels, the periventricular gray may be somewhat arbitrarily divided into a dorsal portion, griseum centrale pars dorsalis (figs. 2 to 4 ), constituting the periventricular gray of the optic tectum, a lateral portion, griseum centrale pars lateralis, and a more ventral portion, griseum centrale pars ventralis (figs. 2 to 4 ). The dorsal periventricular gray is continued caudalward (figs. 5 to 9 ) into relation with the central nucleus of the inferior colliculus (fig. 9) and then disappears. This dorsal portion is not then a part of the tegmentum, has a different functional significance and, according to Castaldi ('23), develops at a different time. It need then receive no further consideration here.

The lateral portion (figs. 2 to 9 ) extends from the diencephalicmesencephalic boundary to the isthmus. Rostrally it is represented by an area of scattered neurons and intermingled fibers to which Castaldi ('24) gave the name of lateroventral nucleus of the central gray. This area disappears caudally and the central subcommissural part of the nucleus of the posterior commissure appears as a differ- 
entiation of the lateral portion of pars lateralis. Behind this nucleus pars lateralis shows no special differentiation but increases in amount and is directly continuous with the inferior collicular gray (fig. 9). It extends directly into the central nucleus of the inferior colliculus and also beneath it, toward the lateral surface of the brain, to become continuous with the band of collicular gray along the ventral and lateral borders of the inferior collicular eminence which is comparable to the layered capsule found in some forms. Pars lateralis disappears slightly in front of the caudal tip of the inferior colliculus.

At its rostral extreme, pars ventralis of the central gray has only a single differentiated area, a small, well defined cell band to which no name has been assigned (fig. 2), but farther caudally it is replaced in part by especially differentiated nuclear groups of the area: the nucleus of Darkschewitseh (Ramón y Cajal, '11) the oculomotor nuelei (figs. 3 to 5 ) and the trochlear nucleus (fig. 6). Behind the trochlear level lies the dorsal nuclens of the raphé (figs. 7 to 10), the rostral tip of which, in the plane of the sections studied, appears in fields which cut the more caudal portion of the superior colliculus and the cephalie tip of the inferior colliculus dorsally and the caudal pole of the interpeduncular nucleus ventrally. The dorsal nucleus of the raphe persists through the rest of the midbrain. Slightly behind its rostral level, the ventral portion of the central gray is replaced, beginning laterally, by the laterodorsal tegmental nucleus (figs. 8 to 10) and then medially by it and by the dorsal tegmental nucleus (fig. 10). Thus, in the caudal half of the midbrain, the ventral portion of the central gray is largely represented by more or less scattered cells between specialized nuclear masses, its diffusely arranged neurons being continuous caudally with similar gray of the periventricular region of the isthmus.

\section{Nuclear groups associated with posterior commissure}

Although various gray centers of the diencephalic-mesencephalic transition area contribute fibers to the posterior commissure, there is an especial differentiation of gray which from the greater specificity of its relations, is recognized as a nucleus of this commissural mass. It shows certain secondary divisions which are termed central subcommissural intracommissural and magnocellular portions.

The intracommissural portion is formed by scattered cells associated throughout most of its extent with crossing commissural fibers. Candalward it passes over without definite demarcation into the tectal periventricular gray.

The main nucleus of the posterior commissure appears in planes slightly behind the habenulo-peduncular tract, as this latter extends 
ventrocaudalward from the habenula, and continues to planes through the rostral tip of the magnocellular portion of the red nucleus (figs. 2 and 3). At its frontal pole it is a more or less discrete precommissural mass lying in relation with the fibers of the posterior commissure, from which, and probably from other sources, it receives impulses. With the inerease of the posterior commissure caudally, the nucleus becomes divided secondarily into a medial portion, pars centralis subcommissuralis, intervening between the undifferentiated lateral part of the periventricular gray and the commissural fibers as they swing ventralward, and a lateral portion the so-called pars magnocellularis which lies lateral to these fibers (and contains intermingled medium-sized and larger cells). The medial and lateral parts of the nucleus of the posterior commissure are interconnected by scattered neurons interspersed among the fibers of the commissure. As the caudal pole of the nucleus is approached, its medial part disappears, being replaced by periventricular gray. Slightly farther caudalward, the lateral part can no longer be identified.

A more ventral mass of gray associated with the fibers of the posterior commissure as they run ventralward to approach the medial longitudinal fasciculus is usually termed the nucleus of Darkschewitsch.

\section{Nucleus of Darkschewitsch}

The rostral tip of this nucleus appears in planes through the interstitial nucleus of Ramón y Cajal, to which it lies immediately medial, but extends caudal to this latter nucleus to planes through the caudal half of the magnocellular portion of the red nucleus (fig. 2). Compared with its size in many other mammals, it is relatively long in the shrew. It overlies and is comparatively near to the medial longitudinal fasciculus. Its neurons are slightly smaller and rather more closely arranged than those of the interstitial nucleus. Its general appearance suggests that it is a differentiated portion of the periventricular gray of the region.

\section{Eye-muscle nuclei}

Ooulomotor complex. Not all of the oculomotor nuclei recognized in some of the higher mammals can be identified in the short-tailed shrew. Such a condition is in agreement with the extremely small size of the eyes and the associated eye-musculature in this form. It has been possible to recognize homologues of the mammalian dorsolateral and ventromedial oculomotor nuclei in this mammal (fig. 5). The EdingerWestphal complex (figs. 3 and 4 ) has also been identified. 
In planes cutting through the superior colliculus dorsally and the interpeduncular nucleus ventrally and passing slightly behind the caudal tip of the red nucleus, a small cluster of multipolar cells appears dorsal to the medial longitudinal fasciculus. This cluster extends caudalward to a plane through both the superior and inferior colliculi. At approximately the same rostral level, a few cells of similar type lie medial to the medial longitudinal fasciculus but these disappear in front of the caudal termination of the dorsally lying group. The dorsal cells represent a very poorly developed dorsolateral nucleus of the oculomotor nerve (fig. 5) and the medially lying cells an even less well developed representative of the ventromedial oculomotor group (fig. 5). In fact, the number and arrangement of the cells are such that they merit the name of nuclei only on the basis of their homologies with larger but similarly placed groups of other mammalian forms.

Nucleus medianus anterior, which has been regarded by some observers (Le Gros Clark, '26, and others) as the rostral end of the Edinger-Westphal complex (fig. 3), is relatively more clearly differentiated in the shrew than any other part of the oculomotor complex. It is a paired nucleus, consisting of two perpendicular bands of rather deeply staining, medium-sized multipolar neurons, appearing among the cells of the rostral part of the linear gray. It passes over without demarcation into the caudal Edinger-Westphal nucleus as described below, rostral to the chief oculomotor gray.

The caudal Edinger-Westphal nucleus (fig. 4) appears to be represented by some smaller neurons located dorsomedial to the dorsolateral oculomotor nucleus through the more cephalic portions of the latter gray and rostral to it, but, like the other oculomotor nuclei, it is exceedingly small and the writers have not been able to trace any root fibers from it into the emerging oculomotor fascicles as yet. As in many other subprimates, it is an unpaired median nucleus (see Ramón y Cajal, '11; Castaldi, '24; and many others).

Trochlear gray. The trochlear nucleus is not directly continuous with the dorsolateral oculomotor nucleus in the shrew as is the case in many other mammals. It appears as scattered neurons lying dorsal to and indenting the dorsal surface of the medial longitudinal fasciculus through planes eutting the superior and inferior colliculi dorsally and the caudal tip of the interpeduncular nucleus and the rostral end of the pons ventrally (fig. 6).

\section{Dorsal nucleus of raphé}

In planes through the caudalmost part of the superior colliculus, at which levels a well differentiated inferior colliculus is also recognizable, the rostral pole of the dorsal nucleus of the raphé makes its 
appearance. Almost immediately it shows a differentiation into a dorsal tip, lateral wings, and a central and a ventral portion (fig. 7). Slightly farther caudalward the dorsal and ventral portions of this nucleus have disappeared but the central part and the lateral wings (figs. 7 to 9 ) fade out into the ventral nucleus of the central gray in levels just in advance of the cephalic tip of the laterodorsal tegmental nucleus. The central portion continues caudalward (figs. 7 to 10 ), in sections ventral to the disappearing lateral tips, as a differentiated cluster of cells, which continues back to the caudal end of the mesencephalon. At all levels, the dorsal nucleus of the raphe is distinguishable from the remainder of the central gray by the closer arrangement and deeper staining of its constituent neurons.

\section{Laterodorsal tegmental nucleus}

In planes so tilted that they show dorsally the eandal half of the inferior colliculus (although the superior collicular gray is still seen in the dorsal part of the field) and ventrally the gray of the pons, a nucleus appears in the lateral part of the ventral portion of the central gray. This nucleus (figs. 8 to 10 ) in the shrew is the representative of the rodent laterodorsal tegmental nucleus (Castaldi, '23). It consists of medium-sized cells which group to form an ovoid nuclear mass (fig. 8) with strands of neurons extending ventrally and ventrolaterally into the underlying tegmental gray. There is, however, no such filtering of the cells of this nucleus ventrolateralward beyond the periventricular gray as is characteristic in certain other mammalian forms. As more caudal planes through the inferior colliculus are approached, the laterodorsal tegmental nucleus increases in size and, in the oblique sections, has a circular outline (fig. 9). At such levels it oceupies the middle part of the ventral portion of the central gray. Soon the circular outline changes to a crescentic form as the gray is followed caudalward and, as the isthmus region is approached, the nucleus gradually decreases in size and the dorsal tegmental nucleus appears on its medial border, filling in the concavity of the crescent (fig. 10). From this point backward through the series, the laterodorsal tegmental nucleus disappears rather rapidly, being reduced to a small cluster of cells, which fades out into the undifferentiated periventricular gray of the pons region. Near the caudal pole of the laterodorsal tegmental nucleus a small, oval patch of deeply staining gray appears for a few sections, lying lateral to the main mass of the laterodorsal tegmental nucleus in the angle of the periventricular gray. It soon takes on a triangular outline and extends slightly behind the caudal pole of the remainder of the laterodorsal tegmental nucleus. This cell cluster is probably 
homologous to the caudal lateral portion of the laterodorsal tegmental nucleus (fig. $10 ; \mathbf{n}$. laterodors. teg. p. lat.) seen in many mammals, which the authors consider the forerunner of the primate nucleus of locus coeruleus.

\section{Dorsal tegmental nucleus}

The dorsal tegmental nucleus is best developed in the isthmus and does not extend far in front of this level. It is a deeply staining mass of rather closely packed neurons, which stands out clearly from the surrounding undifferentiated gray. In the obliquely oriented sections it has a circular outline. Rostrally it appears in the hollow of the crescent-shaped laterodorsal tegmental nucleus (fig. 10). It enlarges caudal to this level and extends back through the isthmus into the pons.

\section{Nucleus of mesencephalio root of $V$}

The nucleus of the mesencephalic root of $V$ (figs. 3 to 10) in the shrew has not been identified in the available material rostral to levels through the caudal end of the superior colliculus and the beginning of the inferior colliculus. At its rostral pole, the nucleus of the mesencephalic root of $V$ (fig. 3) appears in the shrew as relatively large but scattered neurons, grouped in clusters of two or three or lying singly, within the dorsal and lateral parts of the periventricular gray, rarely at its border and rarely in the cuneiform area. Thus they do not show the fairly regular arrangement at the border of the periventricular gray which characterizes their homologues in many mammals. A large proportion of the cells are clearly unipolar but some of the smaller cells appear to have more than one process. The inferior collicular group extends without break into the isthmus group of the nucleus of the mesencephalic root of $V$. In the isthmus, the cells lie along the lateral border of the periventricular gray lateral and ventrolateral to the ventricle and retain this position through levels of entrance of the motor trigeminal root. They form a considerable cluster in the trigeminal region and are conspicuous by reason of their size and deep staining. Among the larger cells there are some of medium size. In these planes through the isthmus the cells are approached by those of nucleus laterodorsalis suggesting the relation between this portion of the nucleus and the nucleus of locus coeruleus of higher mammals.

\section{MIDTEGMENTAL NUCLEAR GROUPS}

Nuclear groups associated with medial longitudinal fasciculus

It is generally recognized that the components of the medial longitudinal fasciculus arise from various sources. However there are 
two nuclear groups that, from their very close positional relationship with the fasciculus in many mammals, can best be considered as particularly related with this fiber bundle. These are the interstitial nucleus of the medial longitudinal fasciculus and the annular nucleus of Castaldi.

The interstitial nucleus of the medial longitudinal fasciculus (figs. 2 and 3 ) is identifiable in planes which cut the pretectal nucleus and the cephalic pole of the superior colliculus dorsally and the rostral tip of the red nucleus and the mammillary body ventrally. At such levels it occupies a position ventral to the magnocellular part of the nucleus of the posterior commissure, lying lateral to the adjacent nucleus of Darkschewitsch, on which it borders, and dorsolateral to the fascieulus. Thus it is outside of the periventricular gray. Ventral and slightly ventrolateral to it, but separated by tegmental gray, is the red nucleus. The interstitial nucleus of the medial longitudinal fasciculus has no great rostrocaudal extent in the shrew for, although it appears rostralward only after the middle portion of the posterior commissure has been reached, it disappears caudally at approximately the same plane as does the magnocellular part of the nucleus of the posterior commissure. At its caudal pole it grades over gradually into the differentiated dorsal part of the deep mesencephalic gray (nucleus mesencephalicus profundus pars dorsalis) which it resembles in cellular character, both nuclear groups having relatively large multipolar neurons.

Except for an occasional neuron no annular nucleus of the medial longitudinal fasciculus is recognizable in the shrew.

\section{Red nucleus}

The cephalic tip of the red nucleus appears in planes through the rostral pole of the superior colliculus dorsally and the mammillary body ventrally and caudal to the frontal tip of substantia nigra. Slightly behind its rostral end, the red nucleus (fig. 2) assumes a circular outline in cross sectional series and, except for a slight modification in its middle portion where the magnocellular and parvocellular divisions overlap, preserves this general configuration to near its caudal pole (fig. 4). The rostral end of the nucleus consists of medium-sized and small multipolar neurons rather loosely scattered throughout the cell mass but soon becoming more densely arranged. This portion which constitutes a pars parvocellularis is replaced gradually in planes through the caudal end of the mammillary body, beginning ventrally and ventromedially, by the larger cells of pars magnocellularis of the nuclear complex (figs. 2 and 3 ). Thus at levels through the cephalic end of the interpeduncular nucleus, the 
red nucleus (fig. 3) has a somewhat ovoid shape and shows secondary subdivision into a large ventromedial portion composed of conspicuous multipolar neurons of pars magnocellularis and a small dorsolateral tip constituted by the cells of pars parvocellularis. Caudal to this plane, pars parvocellularis rapidly disappears but the magnocellular portion increases in size, forming a conspicuous circular mass of large, multipolar cells in the midst of the tegmentum, dorsomedial to substantia nigra (fig. $4 \mathrm{left}$ ). Then the cell group rapidly decreases, as the series is followed caudalward, the capsular portion of the nucleus being very marked slightly behind this plane, with only scattered neurons of the magnocellular type in relation to the ventral tegmental decussation (fig. 4 right). Soon thereafter, in front of the rostral poles of the dorsolateral and ventromedial oculomotor nuclei, as the series is cut, the red nucleus disappears from the field.

\section{Deep mesencephalic gray (nucleus mesencephalicus profundus)}

No well defined deep mesencephalic nuclear groups completely comparable to the various subdivisions of nucleus mesencephalicus profundus, as described by Castaldi ('23) for the guinea pig, are recognizable in the shrew. Suggestions of such groups, however, as well as occasional large, scattered neurons, which presumably belong to this complex, are to be found without definite arrangement intermingled with the tegmental gray. The most conspicuous group of such cells is visible in planes passing through the red nucleus, the magnocellular portion of which is a phylogenetic differentiation of this more specialized tegmental gray (Ariëns Kappers, Huber and Crosby, '36). This group of cells may be considered as constituting a nucleus mesencephalicus profundus pars dorsalis. It appears in planes dorsal to pars parvocellularis of the red nucleus and inereases in cell number in planes caudal to the midportion of this latter nucleus, forming a fairly well developed nuclear group dorsal and dorsomedial to the red nucleus (fig. 3 both sides and fig. 4 left), lateral to the periventricular gray and the interstitial nucleus of the medial Iongitudinal fasciculus, and medial to the undifferentiated tegmental gray of the region. Caudal to this level it disappears rather rapidly in planes slightly behind the red nucleus (fig. 5). For a short distance through the caudal half of the red nucleus, the deep tegmental gray shows a lateral differentiated portion dorsolateral to the red nucleus, which may represent a very small pars lateralis of nucleus mesencephalicus profundus (figs. 4 and 5). Also, between substantia nigra and the caudal capsule of the red nucleus, a few large cells constitute a pars ventralis of this complex (fig. 4). All of these various portions disappear in planes immediately behind the red nucleus, but traces 
of a pars lateralis and a pars ventralis reappear at levels through the superior cerebellar decussation (fig. 5), only to disappear again before the caudal end of this decussation is reached.

\section{Ventral tegmental area}

Between the caudal end of the mammillary body and the cerebral peduncle there is scattered gray which, slightly farther caudalward and dorsalward, is directly continuous with the interstitial nucleus of the commissure of Forel. This gray is representative of the ventral tegmental area (figs. 2 to 4 ) described by Tsai ('25) in the opossum. Through it passes the mammillary peduncle, but there is no clearly defined interstitial nucleus of this bundle such as has been recognized for certain mammals (Papez, '23, '32, and Fox, '41; compare also with descriptions in other papers of this series). The area shows no particular nuclear differentiation in the material studied.

\section{Nucleus medialis profundus}

Nucleus medialis profundus is recognizable in the series available in planes cutting the caudal end of the inferior colliculus dorsally and the pontine gray ventrally. It consists of medium-sized, multipolar neurons forming a somewhat scattered mass of gray ventral to the medial longitudinal fasciculus and continuous, at its caudal end, through the poorly differentiated annular nucleus, with the cells of the laterodorsal tegmental nueleus. Although its constituent neurons are not closely arranged but are intermingled with the undifferentiated tegmental gray of the region, nevertheless nucleus medialis profundus is somewhat more prominent and, on the whole, slightly farther rostral in the shrew than in certain of the other mammals studied in this series (see the account for opossum, Woodburne, ' 43 , and for monkey and man, Crosby and Woodburne, ' $43 \mathrm{c}$ ).

\section{Marginal nucleus of superior cerebellar peduncle}

The term, marginal nucleus of the superior cerebellar peduncle is applied to the gray that lies among the fascicles and around the borders of this fiber system in its course through the brain stem to the region of its decussation. Such cells are of two general types. The bordering cells have the character of undifferentiated tegmental gray; their concentration at the margins of the peduncle being due to the passage of the fiber bundle. Intermingled with the fascicles of the peduncle and along its ventromedial margin, there are neurons of the type of the larger tegmental cells, which become directly continuous with pars dorsalis of nucleus mesencephalicus profundus situated immediately caudal to the red nucleus (see fig. 9). 


\section{Cuneiform area}

This wedge-shaped area is intercalated between the inferior colliculus and the fiber fascicles bordering the periventricular gray and is approximately coextensive with the inferior colliculus. It is a region of passage and synapse of fiber fascicles from tectal areas, of entering fibers of the lateral lemniscus and of scattered, medium-sized multipolar cells (figs. 5 to 9 ).

\section{Certain pretectal and subtectal components of tegmentum}

Pretectal area. Dorsal to the posterior commissure and its associated gray and ventral and rostroventral to the front end of the superior colliculus is a poorly defined area containing widely scattered, small cells which corresponds to the pretectal area of many other forms. It is rostral to the plane of the figures.

Pretectal nucleus. The pretectal nucleus (figs. 2, 3) and the associated large-celled nucleus of the optic tract, which are somewhat less well differentiated in the preparations of the midbrain of the shrew than in those of the bat, occupy a position at the base of the optic tectum. They lie between the posterior nucleus and the optic tectum, the caudal end of the pretectal nucleus extending into relation with the tectal gray internal to stratum opticum. In the material studied it is not possible to make a distinct separation between the large-celled nucleus of the optic tract and nucleus pretectalis. In general, the former nuclear mass is represented by neurons intercalated in the course of the optic system and the pretectal nucleus lies internal to and then caudal to this large-celled nucleus of the optic tract. The cells of the pretectal nucleus are medium-sized and not very closely arranged, and they tend to grade over into the surrounding areas.

Nuclear gray associated with lateral lemniscus. As the lateral lemniscus proceeds forward from its origin in the cochlear nuclei of the brain stem, it lies in relationship with various masses of gray which have somewhat indiseriminately been termed the nuclei of the lateral lemniscus. The most conspicuous of these is a cell mass in the isthmus to which the name of dorsal nucleus of the lateral lemniscus (or parabigeminal nucleus or parabigeminal body) has been applied. This dorsal or parabigeminal nucleus consists of a large-celled lateral portion (fig. 10, left), which forms a dorsolateral eminence on the brain wall just lateral to the periventricular gray, and a small-celled medial portion (fig. 10, right), which spreads out tongue-like between the lateral portion and the periventricular gray. The large-celled lateral portion disappears as the inferior colliculus is approached. 
The small-celled medial portion enlarges somewhat and extends forward along the medial side of the lateral lemniscus as the latter turns into the inferior colliculus. The forward extension of this medial part is comparable to the rostrodorsal part of the dorsal nucleus described in this series of papers for other mammals (fig. 7). The caudal ventral nucleus of the lateral lemniscus, associated with this bundle as it proceeds forward from the bulb to midbrain levels, shows a ventromedial portion of deeply staining, rather conspicuous multipolar neurons and similar cells scattered among the fascicles constituting an intrafascicular part (figs. 6 to 8 ). As the lemniscus proceeds forward toward the medial geniculate body, but directly caudal to the dorsal tip of that nucleus, another gray mass is associated with it, the rostral ventral nucleus of the lateral lemniscus (figs. 5, 6).

\section{MIDLINE NUCLEAR GROUPS}

\section{Linear nuclear gray}

The linear nucleus, as described for the guinea pig by Castaldi ('24), can be identified in the shrew brain but is less well developed in this insectivore than in the rodent. Its rostral portion (n. lin. rost., figs. 2, 3) is represented only by a few deeply staining neurons, arranged in vertical rows, which override the commissure of Forel in planes passing through the cephalic tip of the red nucleus. It begins just rostral to this level and extends caudally to planes through the interpeduncular nucleus. At no level is it more than sparsely represented. A small patch of undifferentiated gray overlying the interpeduncular nucleus marks the position oceupied by its ventral extension in rodents. Through the magnocellular portion of the red nucleus and the fibrous capsule covering its caudal pole, sections show traces of the middle portion of the linear group (nucleus linearis intermedialis, fig. 4) recognizable between the two medial longitudinal fasciculi. They do not extend ventralward to the commissure of Forel, as is the ease in rodents. On the contrary, they are separated from this commissure by undifferentiated gray. Such undifferentiated gray increases in amount in levels through the ventral tegmental decussation and soon all indications of a differentiated linear nucleus disappear. This undifferentiated gray persists for some distance and then a somewhat better developed linear mass appears, the caudal linear nucleus (figs. 5 to 9 ).

The median nucleus of the raphé (figs. 7 to 9), characteristic of the midline area of the rostral end of the pons, overlies dorsally the caudal tip of the interpeduncular nucleus. Since this former nucleus is of pontine nature it will not be discussed further here. 


\section{Interstitial nucleus of commissure of Forel}

The interstitial nucleus of the commissure of Forel (figs. 2 to 4) is represented in the shrew by cells interspersed in the course of commissural fibers as they cross the midline near the rostral end of the midbrain. This gray accompanies the various fascicles which pass out from the commissure toward substantia nigra and the ventrolateral portion of the tegmentum, including the red nucleus. Consequently, in cell material, the interstitial nucleus is represented by horizontal rows of cells in the midline continuous with narrower strands of cells swinging lateralward and ventrolateralward into relation with tegmental gray, substantia nigra and the nucleus of the basal optic root (fig. 4). Rostral and caudal to the commissure of Forel, this interstitial nucleus merges with the undifferentiated gray of the midline. The cells characterizing the interstitial nucleus of the commissure of Forel are medium-sized and well stained but show otherwise no special characteristics.

\section{Interpeduncular nucleus}

Ganser (1882) deseribed the interpeduncular nucleus in the mole. He called attention to the presence of two fypes of cells and emphasized the fact that fascicles of the habenulo-peduncular tract lost their myelin and decussated within the nuclear mass.

The interpeduncular nucleus (figs. 3 to 6 ), which is relatively large in the shrew, has the relations typical for most mammals, since it is placed at the ventral surface of the midbrain between the two cerebral peduncles. Dorsally it is bounded rostrocaudally successively by the interstitial nucleus of the commissure of Forel, the ventral tegmental decussation and the decussation of the superior cerebellar peduncle. In the transverse series stained with toluidin blue the interpeduncular nucleus appears to consist of clusters of medium-sized, relatively unspecialized neurons, with some intermingled smaller cells, intercalated between transversely and obliquely running fascicles, largely those of the habenulo-peduneular tract. This nucleus is found through practically the entire extent of the midbrain of the shrew, for it makes its appearance immediately caudal to the mammillary body and extends back to the pons.

\section{BASAL MIDBRAIN GRAY}

\section{Substantia nigra}

Although the three subdivisions of substantia nigra which are recognizable in many mammals are demonstrable in the shrew, this nucleus is, on the whole, rather small. Pars reticulata (figs. 2 to 5) 
is represented by multipolar neurons intercalated among the deeper fibers of the cerebral peduncle. This portion of substantia nigra appears at the diencephalic-mesencephalic transition region, in planes which cut the mammillary bodies, and extends to levels through the oculomotor nucleus. Caudal to this point an occasional cell among the fibers of the peduncle may be regarded as representative of the more caudal extent of this nucleus in certain other mammals. Its cells are relatively large, multipolar neurons and are more numerous in the rostral and middle thirds than in the caudal portion of the nuclear complex.

Pars compacta of substantia nigra (figs. 2 to 5) appears in planes through the nucleus of the basal optic root (nucleus tractus peduncularis transversi) as a narrow band of gray extending from the dorsal tip of this latter nucleus laterally over the medial part of the peduncle (fig. 2). It spreads out over the peduncle in a thin sheet with thickenings laterally and medially and then becomes confined to the medial part of this fiber mass (fig. 3). Still farther caudalward it enlarges dorsomedially (fig. 4), its cells becoming confluent with those of the interstitial nucleus of the commissure of Forel. Caudal to this interstitial nucleus it flattens down again, consisting then of two portions (fig. 5), a medial portion dorsomedial to the peduncle, which is continuous with the mass farther forward, and a narrow band of more nearly linearly-arranged cells, which overrides the dorsal portion of the peduncle but does not reach its lateral border. Both of these portions disappear in planes rostral to the tip of the oculomotor nucleus (compare right and left side of fig. 5).

Pars lateralis of substantia nigra (figs. 4 and 5) is small and poorly differentiated in the shrew. It appears at levels through the medial geniculate nucleus (fig. 4 left) between this nucleus and the peduncle. At levels behind this nucleus, pars lateralis overrides the lateral part of the peduncle and extends dorsalward along the course of nigro-tectal fascicles. It disappears caudally in planes approximately through the rostral pole of the oculomotor nucleus.

\section{Nucleus of basal optic root}

This nucleus has been very recently described by Gillilan ('41) from the material of the shrew brain available for study. Its position is indicated in figures 2 and 3 but no further account is necessary, except to state that this cell mass has the appearance of being a special derivative of substantia nigra. 
PART II. THE BAT

THE PERIVENTRICULAR GROUPS

General areas of periventricular gray

In the bat, as in the shrew, the term periventricular gray is applied to neurons surrounding the ventricle which do not show arrangement into specific nuclear groups. This periventricular or central gray can be divided into the customary dorsal, lateral and ventral portions. The dorsal portion (figs. 12 and 13) shows a tendency toward a bilateral differentiation with the midline oceupied either by cells intercalated in fiber bundles or by a deeply staining median band of neurons. This dorsal portion appears immediately caudal to the posterior commissure and extends back to planes in which the cerebellum pushes forward between the two inferior colliculi, at which levels the dorsal portion of the periventricular gray is continuous with the main cell mass of the inferior colliculus.

The lateral portion of the central gray (figs. 11 to 14) extends from planes slightly caudal to the rostral tip of the dorsal portion of the periventricular gray to levels caudal to the caudal pole of the latter mass. Thus it is still present in sections through the frontal end of the laterodorsal tegmental nucleus. It shows no special differentiation except the central subcommissural part of the nucleus of the posterior commissure. It is extremely small in its caudal third, where it is represented by a tiny mass of gray, which lies at the lateral tip of the ventral portion of the periventricular gray and is continuous with the chief or central nucleus of the inferior colliculus.

The term ventral portion of the periventricular or central gray (figs. 11 to 15) is applied to the less differentiated neurons of the ventral part of the periventricular field. Throughout practically its whole extent, which is coincident with that of the mesencephalon, it consists of medium-sized, nonspecifically stained neurons intermingled with occasional larger cells which occupy those portions of the ventral field not held by differentiated nuclear masses. Thus it varies from level to level in amount, for although in some planes it occupies practically the whole ventral periventricular field, in others, particularly caudally, it is reduced to small patches of intercalate neurons interposed between differentiated nuclear groups.

\section{Nuclear groups associated with posterior commissure}

The nuclear gray associated with the posterior commissure is comparable to that described for the shrew. 
The nucleus of the commissure (figs. 11, 12) shows a marked relation to the surrounding cell areas, suggesting that its medial portion pars centralis subcommissuralis is derived from the lateral part of the periventricular gray and its lateral portion, which has some intermingled larger cells constituting it a pars magnocellularis, from the tegmental gray of the region. It lies in the plane in which the posterior commissure fibers turn ventralward, the lower pole of the nucleus being adjacent to the nucleus of Darkschewitsch. The intracommissural part of the nucleus of the posterior commissure (figs. 11, 12 ) is poorly developed on the whole, being represented only by a very few neurons interspersed among the decussating fibers.

\section{Nucleus of Darkschewitsch}

The nucleus of Darkschewitsch (fig. 11) is situated dorsal to the medial longitudinal fasciculus and ventral to the main nucleus of the posterior commissure. Medial to it lies the interstitial nucleus of the medial longitudinal fasciculus which extends caudal to it. The nucleus of Darkschewitsch is exceedingly difficult to delimit in the bat. So far as the writers have been able to determine, it is represented in this form only by a few scattered cells intercalated in the course of the ventrally running posterior commissure fibers. Actually it is situated in approximately the transverse plane of the posterior commissure but the tilt of the sections makes it appear to lie slightly caudal to this decussating system.

\section{Eye-muscle nuclei}

The oculomotor and trochlear nuclei of the bat, like those of the shrew, are relatively poorly developed, in accordance with the small size of the eyes and eye-muscles in these forms. There are, however, certain differences in the systems, for in the bat the oculomotor gray - and particularly its ventromedial nucleus - is larger than the trochlear complex, and there is a better separation between the oculomotor and trochlear nuclear masses.

Oculomotor complex. In the sections studied, which have an oblique tilt, the oculomotor nuclei make their appearance in planes which cut the superior colliculus and the frontal tip of the inferior colliculus dorsally and the hypothalamus ventrally. Such an oblique plane passes rostral to the cephalic end of the red nucleus although undoubtedly in transverse planes the oculomotor nuclei begin slightly behind the frontal pole of the red nucleus. $A$ ventromedial and a dorsolateral oculomotor nucleus can be identified in the bat but the two nuclei grade over into each other (fig. 13). They appear at 
about the same level rostrally but the ventromedial is somewhat the larger of the two. In sections through the dorsal tegmental decussation, these groups form a single eell mass situated at the dorsomedial angle of the medial longitudinal fasciculus. This mass maintains the relations described to levels which show both the small-celled and largecelled constituents of the red nucleus. The oculomotor nucleus then thins out rapidly and disappears just rostral to the caudal tip of the red nucleus.

It is difficult to be certain that a nucleus medianus anterior (rostral Edinger-Westphal nucleus of Le Gros Clark, '26, and others) is present in the bat, but parallel strands of cells (fig. 13) continuing rostroventrally in front of the oculomotor complex and in intimate relation with the rostral linear group presumably represent this nuclear mass. These neurons resemble those of the Edinger-Westphal nucleus proper or caudal Edinger-Westphal nucleus.

The Edinger-Westphal nucleus (fig. 13), the caudal EdingerWestphal nucleus of certain observers, is represented on either side by a band of gray which lies close to the midline between the two dorsolateral oculomotor nuclei in planes through the parvocellular portion of the red nucleus. In cell type it resembles preganglionic centers, its neurons being smaller than those constituting the dorsolateral and ventromedial oculomotor nuclei and having smaller Nissl granules. It should be emphasized that this portion of the oculomotor complex is exceedingly small in the bat, persisting for only a few sections.

Trochlear gray. The trochlear nucleus (fig. 14) is separated from the caudal tip of the oculomotor group by a minimal distance. It has the usual relations, indenting the dorsal surface of the medial longitudinal fasciculus, but has only a very short extent (not exceeding $100 \mu)$.

\section{Dorsal nucleus of raphé}

The dorsal nucleus of the raphe is not so well developed in the bat as in certain other mammalian forms (for example, rodents). From its cephalic tip (fig. 13), found in planes through the trochlear nucleus, it extends caudalward to the pons region (fig. 15). Throughout its extent it lies near the midline, dorsomedial and sometimes slightly medial to the medial longitudinal fasciculus. In the midbrain it consists of two small, parallel rows of neurons extending from the ventricular floor to a position between the two medial longitudinal fasciculi. In levels immediately rostral to the frontal pole of the dorsal tegmental nucleus, the dorsal nucleus of the raphé consists of three portions, the most dorsal of which is a tiny patch of cells 
just under the ventricle. This patch extends for only a few sections and then disappears. Ventral to it is a lightly staining cluster of scattered gray, forming the central portion (fig. 14) of the dorsal nucleus of the raphé, and beneath this central portion is a deeply staining ventral tip (fig. 15). Farther forward this dorsal nucleus of the raphe is intercalated in the midline between the two laterodorsal tegmental nuclei. Toward its rostral pole, clusters of cells appear on either side of the main mass of the nucleus which correspond to the more differentiated lateral wings characteristic of the nuclear group in certain other forms. These lateral wings persist to the rostral pole of the nucleus, fading out there into the ventral nucleus of the central gray.

\section{Laterodorsal tegmental nucleus}

The laterodorsal tegmental nucleus (fig. 15) begins in front of the rostral end and terminates just before the caudal pole of the dorsal tegmental nucleus. It differentiates in the region of the ventral nucleus of the periventricular or central gray and is surrounded on nearly all sides by the scattered cells of this latter nuclear mass. At some levels, and particularly in its more caudal portions, strands of neurons extend from the laterodorsal tegmental nucleus into the underlying tegmental gray, to become intermingled with the poorly developed dorsal part of nucleus mesencephalicus profundus (fig. 15). The laterodorsal tegmental nucleus, although relatively large, is not sharply circumscribed, its cells being less compactly arranged and less differentially stained than those of the dorsal tegmental nucleus on which it borders (fig. 15). In close approximation to it laterally are the conspicuous neurons of the nucleus of the mesencephalic root of the trigeminal nerve (fig. 15).

\section{Dorsal tegmental nucleus}

The dorsal tegmental nucleus, in the oblique series studied, extends from planes that cut the cerebellum and inferior colliculus dorsally and the caudal end of the interpeduncular nucleus ventrally to those passing through the upper border of the pons. Thus, for much of its extent, it lies in the isthmus (fig. 15), its rostral half at levels through the dorsal nucleus of the lateral lemniscus (fig. 15, n.dors.lem.lat.p. caud.dor.). Throughout this extent it is in the midst of the periventricular gray, near the midline and just lateral to the dorsal nucleus of the raphé. Ventral and slightly ventromedial to it is the medial longitudinal fasciculus and lateral is the laterodorsal tegmental nucleus, but it is separated from these structures by the 
scattered cells of the ventral nucleus of the central gray. The dorsal tegmental nueleus consists primarily of densely arranged, conspicuously darkly stained neurons, the mass having, in the oblique series studied, an approximately circular outline.

\section{Nucleus of mesencephalic root of $V$}

In the bat, the rostralmost cells of the mesencephal:c root of $\mathrm{V}$ (fig. 12) are found immediately behind the beginning of the posterior commissure and the caudalmost cells occur at the level of entrance of the trigeminal nerve (just caudal to fig. 15). Between these limits there are two major divisions of this nuclear groupa rostral or superior collicular group and a caudal portion found at trigeminal levels and extending forward through the greater part of the isthmus. The rostral or superior collicular group (fig. 12) consists of clusters of cells lateral to the ventricle along the outer edge of the periventricular gray. Some of these are found in each section although at no level are they particularly numerous. They are deeply staining, thus relatively conspicuous, and of approximately the size of the motor neurons of the oculomotor nerve. Therefore, these cells are proportionately smaller than those in many mammals. They decrease through inferior collicular levels (figs. 13, 14), being reduced to an occasional neuron or small cluster of neurons. Then the number of cells increases at the angle of the ventricle as the sections are run through the isthmus toward trigeminal levels (fig. 15), so that there is a considerable collection of these neurons in trigeminal and pretrigeminal levels. These lie dorsal to the motor nucleus of the trigeminal and lateral and ventrolateral to the angle of the ventricle. In size and staining characteristics, the groups in the isthmus and at trigeminal levels correspond to those of the superior collicular group.

\section{MIDTEGMENTAL NUCLEAR GROUPS}

\section{Nuclear groups associated with medial longitudinal fasciculus}

As in the shrew, two nuclear groups are intimately associated with the medial longitudinal fasciculus in the bat: the interstitial nucleus of the fasciculus and the annular nucleus.

The interstitial nucleus (figs. 11, 12) overlies the medial longitudinal fasciculus at levels caudomedial to the rostral pole of the nucleus of Darkschewitsch and it extends caidalward, medial to and then behind this latter nuclear mass, to planes just rostral to the oculomotor group. It is surrounded dorsomedially, ventromedially, rostrally and caudally by the undifferentiated gray of the periventricular 
region, from which it is distinguishable through the more compact arrangement and the slightly deeper staining of the constituent neurons. In midsections this nucleus has an oval outline but tapers down at both poles. At no level is it a large nucleus.

Nucleus annularis (Castaldi, 23) is represented in the bat only by scattered neurons or by tiny clusters of cells (figs. 14) usually in relation with the lateral or ventrolateral side of the medial longitudinal fasciculus. Such cells are found only in the rostral portion of the mesencephalon. None has been recognized in planes caudal to the trochlear nucleus. They are distinguishable by their rather. deep staining and by their position.

\section{Red nucleus}

In the available material the red nucleus appears (fig. 13) rostrally in planes through the oculomotor nuclei and extends caudally to levels in which the trochlear nucleus is just beginning to make its appearance (fig. 14). This slight caudal extent of the red nucleus is probably more apparent than real due to the oblique tilt of the sections, the ventral part of the field being far rostral to the dorsal part. On the whole, the red nucleus in the bat is somewhat less well developed than in many subprimates, although parvocellular (fig. 13, right) and magnocellular (fig. 13, right and left) groups are recognized. The parvocellular portion, which consists of medium-sized and small cells, occupies the rostral tip of the nucleus. In planes through the cephalic part of the dorsal tegmental decussation there is still a considerable parvocellular element but, as the caudal part of this decussation is approached (fig. 13), the parvocellular portion becomes confined to the dorsal region of the nucleus and the ventral part of the nucleus is large-celled. Soon thereafter, the parvocellular portion disappears. The magnocellular part extends only a short distance farther caudally, being represented by a few scattered cells (fig. 14), and then fades out of the field.

\section{Deep mesencephalic gray (nucleus mesencephalicus profundus)}

For the most part, the general tegmental gray shows very little differentiation in the bat, even less, if possible, than in the shrew. The only arrangement recognizable is that impressed upon the masses of gray by the fibers of passage. Occasionally, however, clusters of differentiated, larger cells suggest the various parts of the nucleus mesencephalicus profundus of rodents and of certain other mammalian forms. As representative of these is a group of neurons (fig. 12) dorsal to and slightly in front of the red nucleus, lateral 
to the periventricular gray and ventral to the superior colliculus. This patch of cells, a nucleus mesencephalicus profundus pars dorsalis, is fairly well developed for a short distance in these more cephalic planes but is reduced as the red nucleus appears in the field, although it has some representation. In planes just rostral to and through the superior cerebellar decussation, a group of similar cells makes its appearance in approximately the same position. This group, which constitutes a very poorly differentiated caudal portion of pars dorsalis, persists to the caudal end of the midbrain (figs. 14, 15). In levels showing this caudal portion of pars dorsalis, similar cells occur in the ventral part of the field and might be considered as forming a caudal portion of pars ventralis of nucleus mesencephalicus profundus. This ventral portion does not find representation farther forward with the exception of three or four cells in a single section between the red nucleus and substantia nigra, in planes through the parvocellular portion and the beginning of the magnocellular part of the red nucleus. In addition to the poorly differentiated pars dorsalis and pars ventralis just described, there are, at various levels, occasional neurons of this larger tegmental type. They are few in number and show no nuclear pattern.

\section{Marginal nucleus of the superior cerebellar peduncle}

The nucleus associated with the superior cerebellar peduncle (fig. 15 ) is most clearly seen in the isthmus, where it follows the forward running fascicles from the lateral border of the peduncle rostralward, ventralward and slightly medialward to become continous with the caudal portion of pars dorsalis of nucleus mesencephalicus profundus at levels at which the superior cerebellar peduncle decussates. This nucleus consists of multipolar cells of the type of the larger elements of the tegmental gray, which are found along the margin and are intercalated among the bundles of the superior cerebellar peduncle.

\section{Cuneiform area}

The cuneiform area in the bat (fig. 14) occupies the usual position in the angle between the inferior colliculus and the periventricular gray. It consists of multipolar neurons, of spindle to triangular shape, interspersed with fibers of passage which are partly tectal in origin and in part consist of fascicles from the lateral lemniscus. The area is practically coextensive with the inferior colliculus.

Ventral tegmental area and nucleus of mammillary peduncle

The terin ventral tegmental area (not labeled) may be applied in the bat, following the nomenclature of Tsai ('25) for the opossum, 
to the more or less scattered mass of cells intervening between the cerebral peduncle and the interpeduncular nucleus. Rostrally it begins immediately behind the mammillary body and caudally it fades out into the pontine gray. Through the upper half of this area, the mammillary peduncle (fig. 14) passes dorsoventrally to reach a position at the ventral surface of the brain. Particularly in the dorsal part of the area, neurons are concentrated somewhat along the fascicles of this peduncle (fig. 14), constituting a rather poorly differentiated nucleus of the mammillary peduncle (as designated by Papez, '23; see also Fox, '41). Such cells may be a trifle more spindleshaped, due perhaps to their orientation, than the other neurons of the region and possibly more deeply stained than the surrounding gray. On the whole, this region in the bat brain is relatively compressed and the ventral tegmental gray is confined within somewhat smaller limits than in certain of the other mammals considered.

\section{Nucleus medialis profundus}

\section{Nucleus ventralis tegmenti of von Gudden}

Nucleus medialis profundus (fig. 15) is a not very sharply circumscribed, small group of scattered, multipolar neurons situated ventrolateral and somewhat lateral to the medial longitudinal fasciculus, in planes through the rostral midportions of the dorsal tegmental nucleus and the laterodorsal tegmental nucleus. It is comparable to the better defined, similarly termed cell mass described for rodents by Castaldi ('24) and found in the shrew and other mammals studied.

\section{Certain pretectal and subtectal components of tegmentum}

Pretectal area. A poorly delimited gray area above the posterior commissure and rostroventral and ventral to the cephalic tip of the superior colliculus represents the pretectal area in the bat. It is not illustrated in the figures.

Pretectal nucleus. The pretectal nucleus (fig. 11) in the bat lies at the base of the optic tectum, intervening between this midbrain area and the medial geniculate nucleus. It passes over without sharp demarcation into stratum griseum intermediale caudally but farther rostrally is somewhat more clearly separated from the frontal extremity of this tectal mass. It lies partly in plane with and partly dorsal to the plane of the posterior commissure. Its cells are medium-sized and not differentially stained, the limits of the nucleus being indistinct.

Nuclear gray associated with lateral lemniscus. Along the course of the lateral lemniscus as it proceeds forward through the isthmus and in those midbrain levels in which it enters the inferior colliculus, 
there are rather numerous strands of deeply staining cells, varying in number and in definiteness of arrangement from level to level. Various members of this group have been termed nuclei of the lateral lemniseus. There is a relatively large dorsal nucleus of the lateral lemniscus (fig. 15), situated close to the ventricular floor between the laterodorsal tegmental nucleus and the nucleus of the mesencephalic root of $\mathrm{V}$ medially and the inferior colliculus laterally. Its rostral extreme (the rostrodorsal part of the dorsal nucleus of the lateral lemniscus) is not illustrated. Caudalward, as the inferior colliculus decreases in size, the dorsal nucleus increases and differentiates into a smaller-celled medial and a larger-celled lateral portion. The nucleus continues for a short distance behind the caudal tip of the inferior colliculus and then disappears. It is in obvious relation with fibers of the lateral lemniscus.

Both rostral ventral and caudal ventral nuclei of the lateral lemniscus are present. The rostral ventral, which consists of an indeterminate mass of cells just caudal to the medial geniculate nucleus is shown in figure 13. The caudal ventral nucleus is more conspicuous. It consists of a ventromedial and an intrafascicular division. The ventromedial is a more closely grouped mass of cells associated with the lateral lemniscus, caudal to the planes illustrated, but similar to that shown in the shrew (figs. 6 to 8 ). The intrafascicular part of the caudal ventral nucleus resembles, in cell character, the ventromedial part but is characterized by the distribution of its cells among the fascicles of the lateral lemniscus (fig. 15).

\section{MIDLINE NUCLEAR GROUPS}

\section{Linear nuclear gray}

The rostral tip of the linear nucleus lies in the cephalic end of the mesencephalon, in planes cutting the inferior colliculus dorsally, the medial geniculate nucleus laterally and the mammillary body ventrally. It is situated between the two medial longitudinal fasciculi, extending ventrally in the midline to a position above the commissure of Forel (fig. 13).. As this commissure enlarges, the rostral portion of the linear nucleus becomes reduced to a small band between and immediately ventral to the medial longitudinal fasciculi. Caudal to the commissure, the linear nucleus is represented only by a small mass of gray lying between the medial longitudinal fasciculi and the dorsal tegmental decussation. Still farther caudalward, in planes through the ventral tegmental decussation, it extends ventralward again as the intermediate portion of the linear nucleus. This intermediate portion becomes differentiated at its caudal end (fig. 14) 
and then is forced out of the field by the superior cerebellar decussation. Behind this decussation the nucleus extends ventralward (fig. 15) as the caudal linear group, which in turn is replaced by the medial nucleus of the pontine raphé.

\section{Interstitial nucleus of commissure of Forel}

The interstitial nucleus of the commissure of Forel has relations in the bat similar to those already described for the shrew. In part it is represented by cells intercalated in the course of the crossing fibers (fig. 13) and in part by rather more densely arranged masses of neurons extending along the course of the commissural fibers to become continuous with the red nucleus, substantia nigra and the nucleus of the basal optic root (fig. 13).

\section{Interpeduncular nucleus}

The interpeduncular nucleus (figs. 14, 15) is situated in the midline on the ventral surface of the mesencephalon between the two cerebral peduncles but separated from them, through part of its extent, by the mammillary peduncle and by the nucleus of the basal optic root. It consists of bands of crossing fibers between which are clusters of moderately stained, medium-sized neurons, which show no special cellular characteristics. A definite fibrous capsule covers its caudal pole.

\section{BASAL MIDBRAIN GRAY}

\section{Substantia nigra}

The rostral tip of substantia nigra (fig. 12) appears between the cerebral peduncle and the medial geniculate nucleus. Ventromedial to it, and riding over the peduncle, is nucleus subthalamicus. This small tip of substantia nigra enlarges as it is followed caudally in the series (fig. 13, left) and, in planes behind the medial geniculate nucleus, extends slightly dorsally. It seems probable that this portion represents a pars lateralis of substantia nigra. Slightly farther caudalward this portion becomes continuous (fig. 13, right) with pars compacta of substantia nigra and then disappears.

Pars compacta of substantia nigra (figs. 13, 14) is relatively small in the bat. It makes its appearance caudal to the rostral end of pars lateralis, as a band of darker staining but scattered cells which, farther caudalward, show a somewhat linear arrangement as they lie along the medial angle of the peduncle. Behind the caudal tip of pars lateralis, pars compacta decreases rapidly in size and soon disappears, before the caudal end of the cerebral peduncle is reached. 
Pars reticulata of substantia nigra (figs. 13, 14) is composed of large, scattered, multipolar neurons among the fibers of the peduncle, superficial to pars compacta. Rostrally, in front of the rostral tip of pars compacta, pars reticulata is represented by only a few scattered cells. It becomes a recognizable nuclear group at about the same planes as does pars compacta. As this compact portion shifts medialward, pars reticulata also occupies a more medial position among the fibers of the peduncle, its cells being numerous at these levels. It is never, however, a large nuclear mass, and it too disappears before the caudal end of the peduncle is reached.

\section{Nucleus of basal optic root}

This nuclear mass has recently been described from the available material by Gillilan ('41). Consequently, no further account of it will be given in the present paper, although it is illustrated in figure 14.

\section{SUMMARY}

The differentiation of the midbrain of the bat and the shrew is in line with the reduced optic and large auditory systems in these animals and with the exaggerated development on the one hand, and the reduced differentiation on the other hand, of other brain centers in these forms.

The more caudal nuclear members of the periventricular group in both these mammals are better developed than the rostral representatives. Thus the central subcommissural portion of the nuclear gray of the posterior commissure and the nucleus of Darkschewitsch are small. Eye-muscle nuclei are relatively poorly developed in the shrew and the bat, the trochlear complex being larger in the former mammal and the oculomotor in the latter. The Edinger-Westphal nuclear groups are greatly reduced in both forms. The dorsal nucleus of the raphé is relatively large, particularly in the bat, and the dorsal tegmental nucleus and the laterodorsal tegmental nucleus are well represented in both mammals.

On the whole, the midtegmental nuclear groups are not particularly well represented. Both portions of the red nucleus are relatively somewhat smaller in these forms than in many other mammals, and the associated groups of teg- 
mental cells of similar type assigned to the deep tegmental gray are indistinct and at some levels entirely lacking. On the other hand, nucleus medialis profundus or the ventral tegmental nucleus of von Gudden is relatively prominent and rather far rostral in the shrew, although poorly circumscribed in the bat. The interstitial nucleus associated with the medial longitudinal fasciculus is relatively small and there are no distinct representatives of an annular nucleus in either the bat or the shrew.

The interpeduncular nucleus, belonging to the midline group, is relatively large in the shrew and of about medium size in the bat. The linear groups are rather poorly developed in both mammals. The nuclei associated with the commissural systems of the tegmentum of the midbrain show no special size or pattern.

The nuclei associated with the lateral lemniscus are well developed, a fact in line with the marked development of other centers of the auditory systems in both forms, but particularly in the bat.

Among the basal nuclear group of the midbrain, pars lateralis of substantia nigra is comparatively better developed in the bat than other portions of that nuclear mass, but poorly represented in the shrew. Pars compacta and pars reticulata are small, with a reduced caudal extent, in both mammals.

PLATES 1 TO 10

EXPLANATION OF FIGURES

1 Ontline drawing of a sagittal section through the brain of the shrew for orientation of the photomierographs of figures 2 to $10 . \times 10$.

2 to 10 Photomicrographs of transverse sections through the midbrain and isthmus of the short-tailed shrew. The tilt of the sections is indicated in figure 1. Toluidin blue preparations. $\times 30$.

11 to 15 Photomicrographs of oblique sections eutting the midbrain and isthmus regions of the brain of the bat in planes indicated on figure 16 . Toluidin blue preparations. $\times 35$.

16 Photomierograph of a sagittal seetion through the brain of the bat to serve as an orientation figure. Toluidin blue preparation. $\times 18$. 
PLATE 1

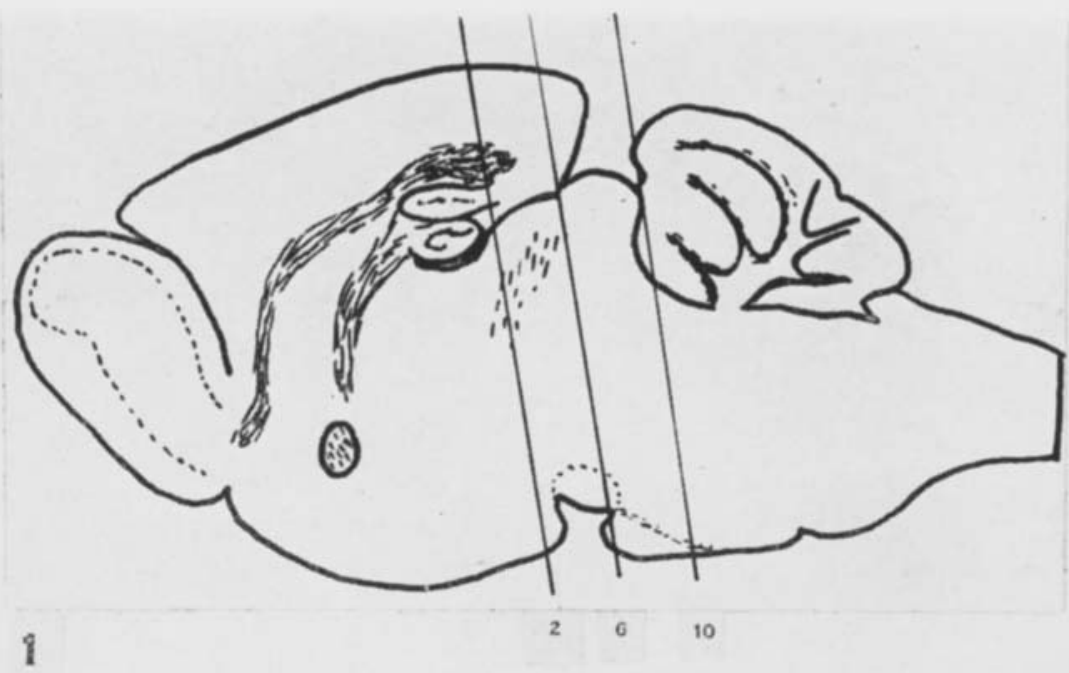

N.INTRACOM. COM.POST. GR.CENT.P.DORS. N.DARKSCH.

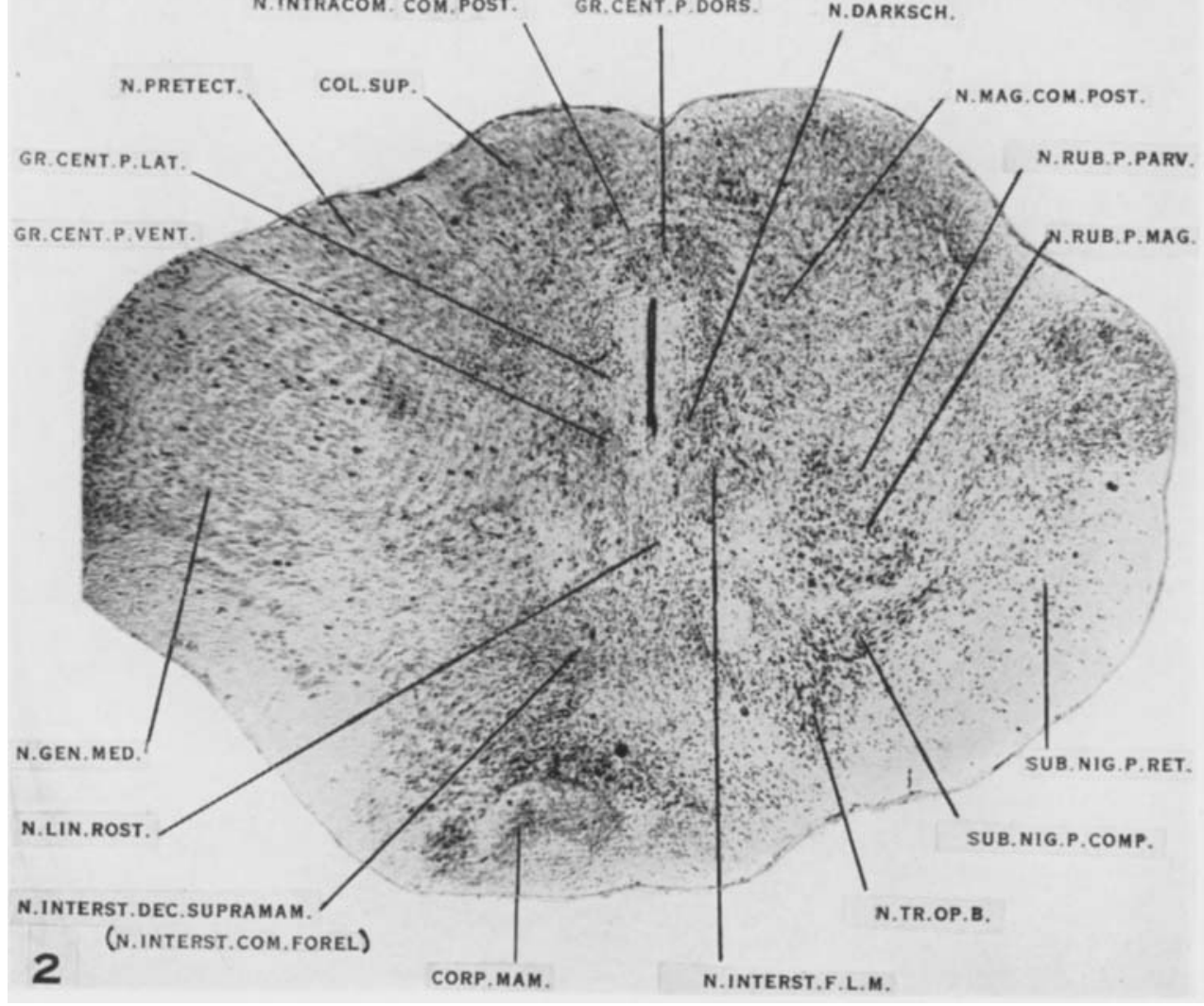


PIATE 2

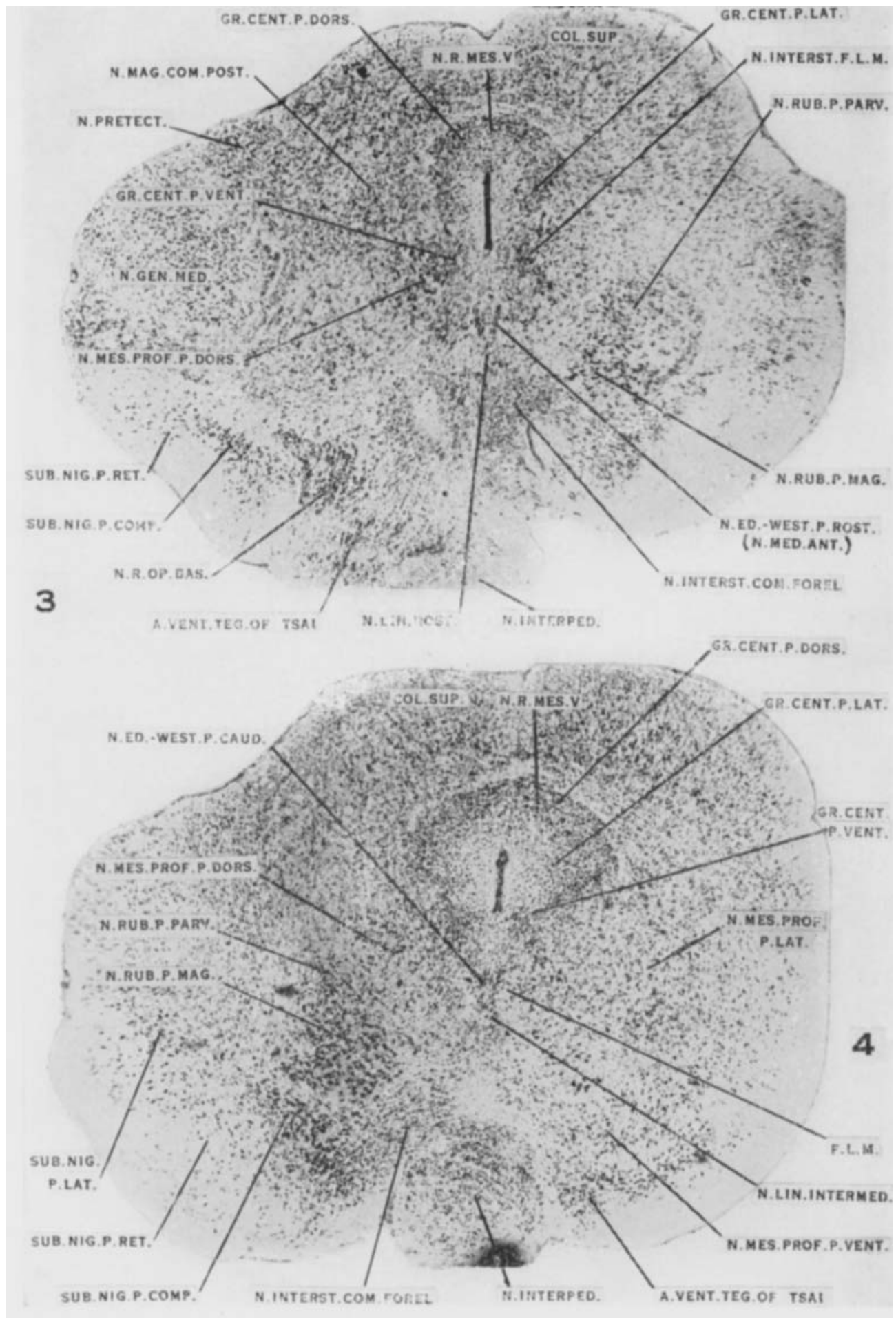


PLATE 3

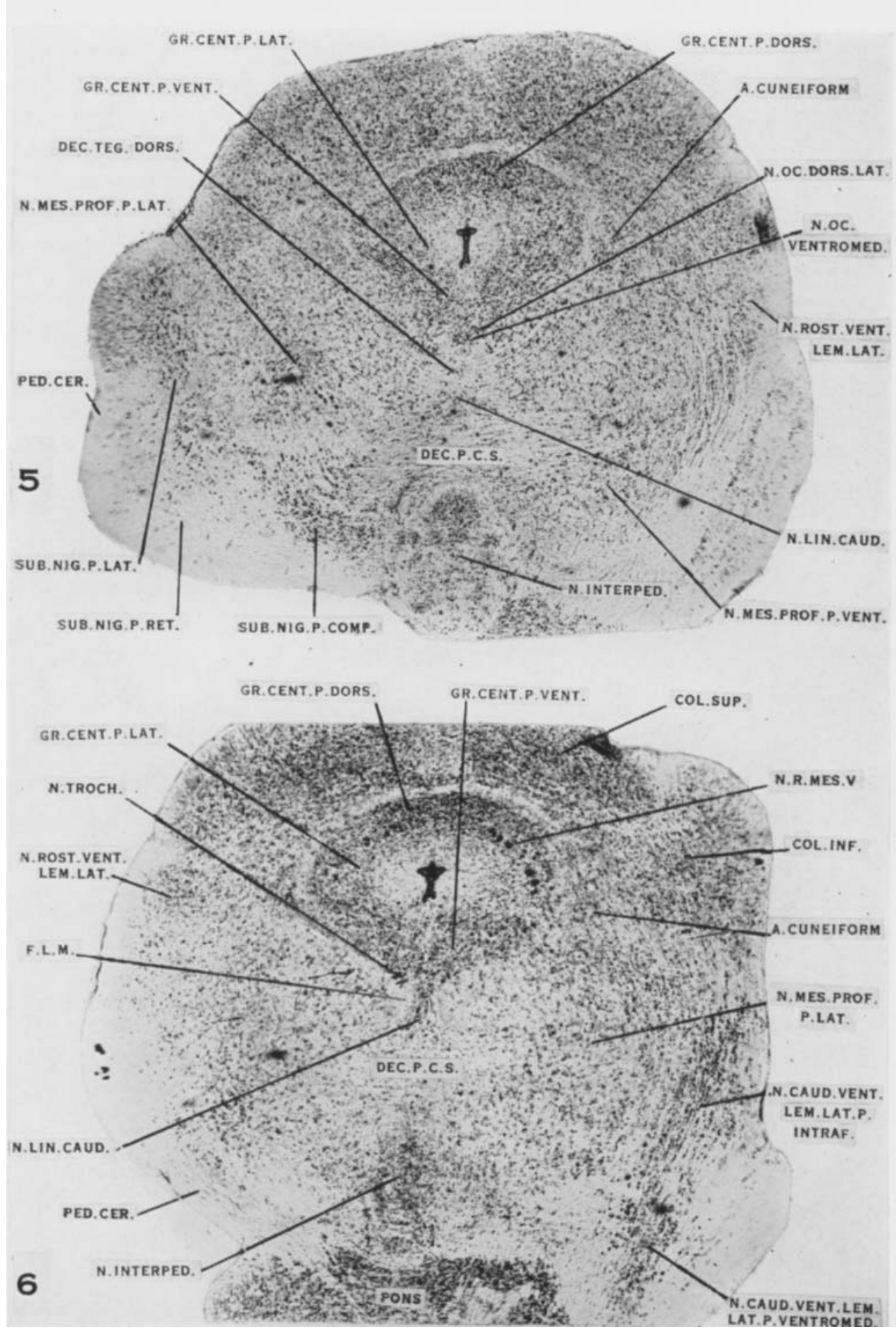




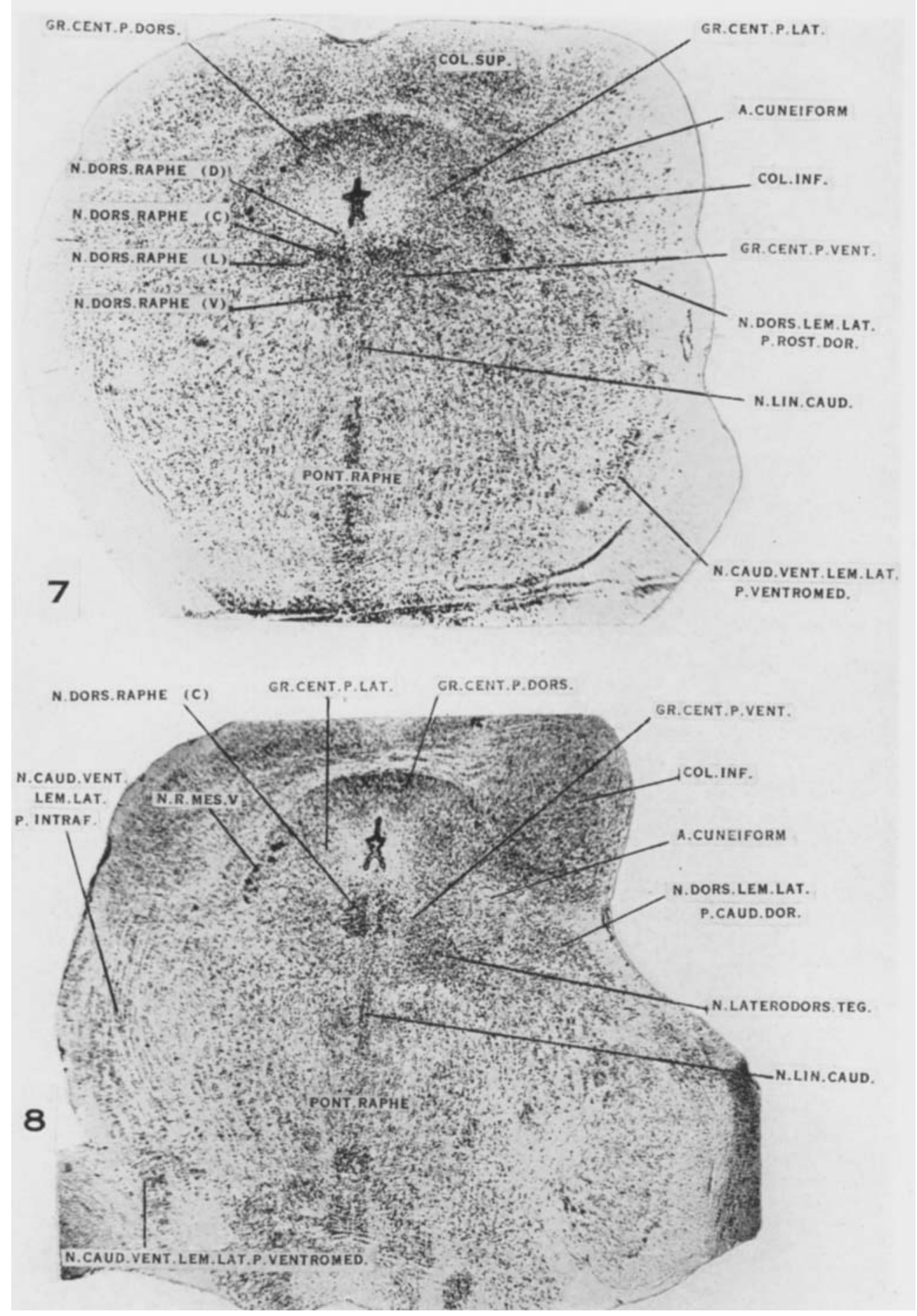


PLATE 5

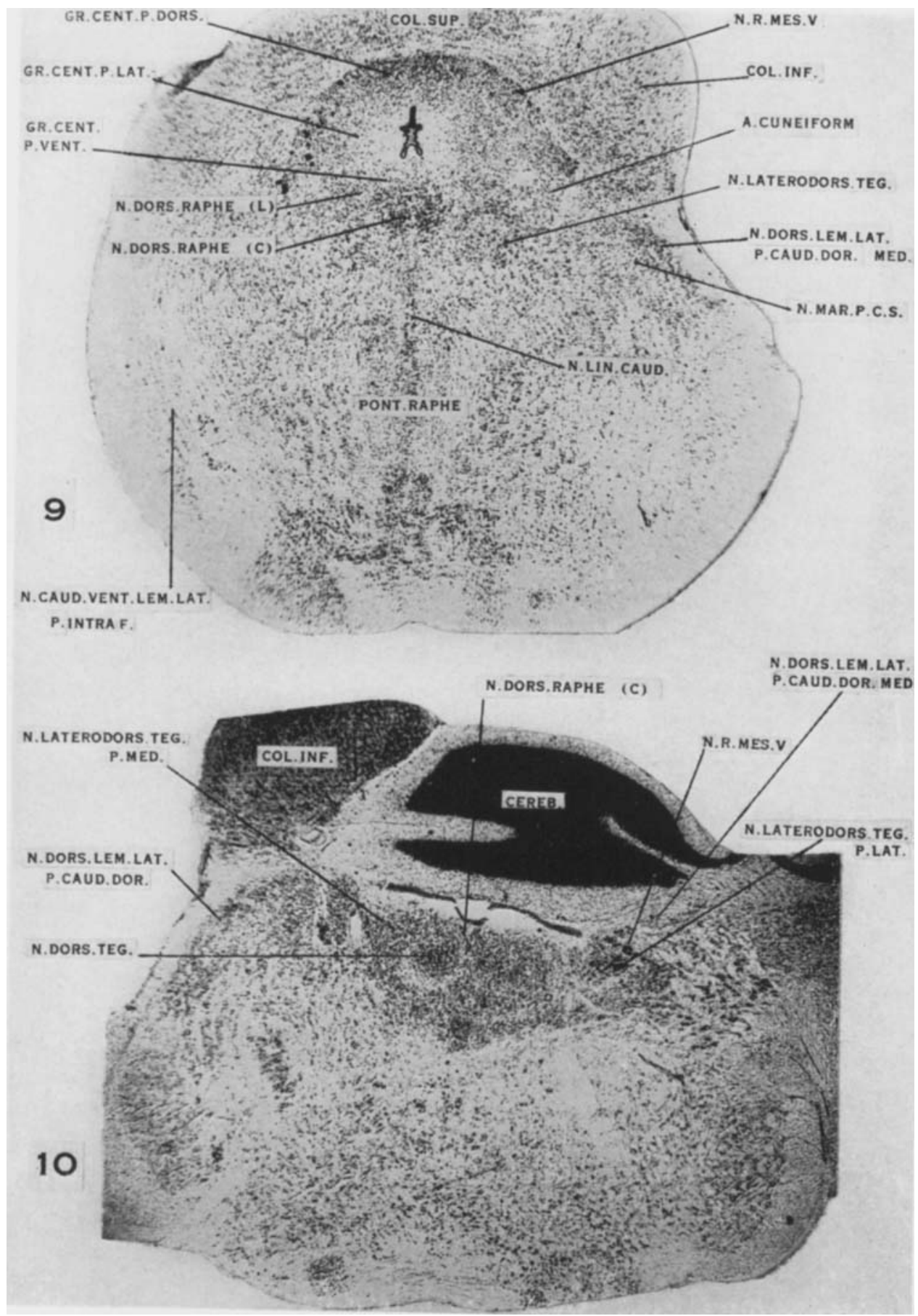




\section{PLATE 6}

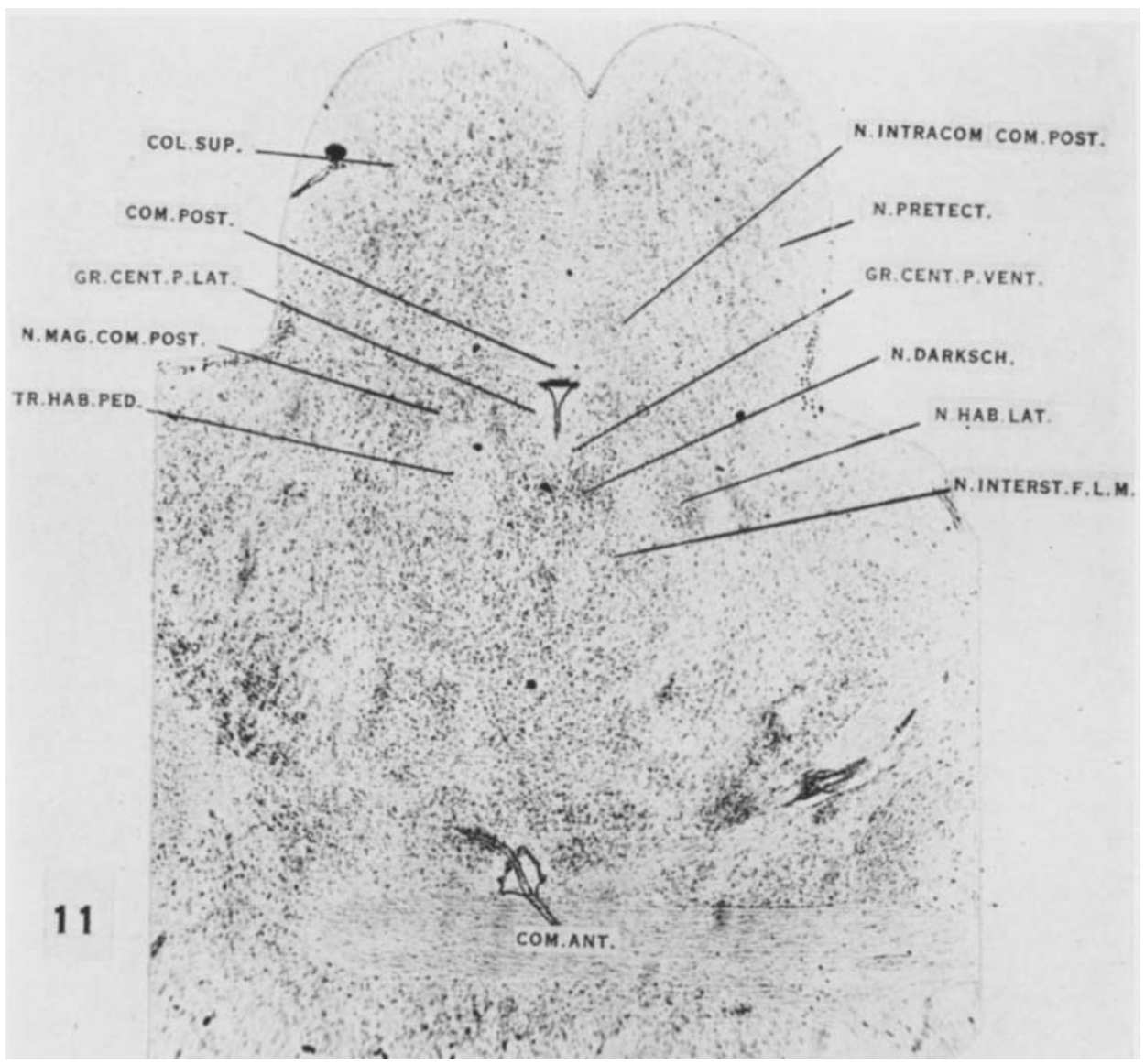




\section{PLATE 7}

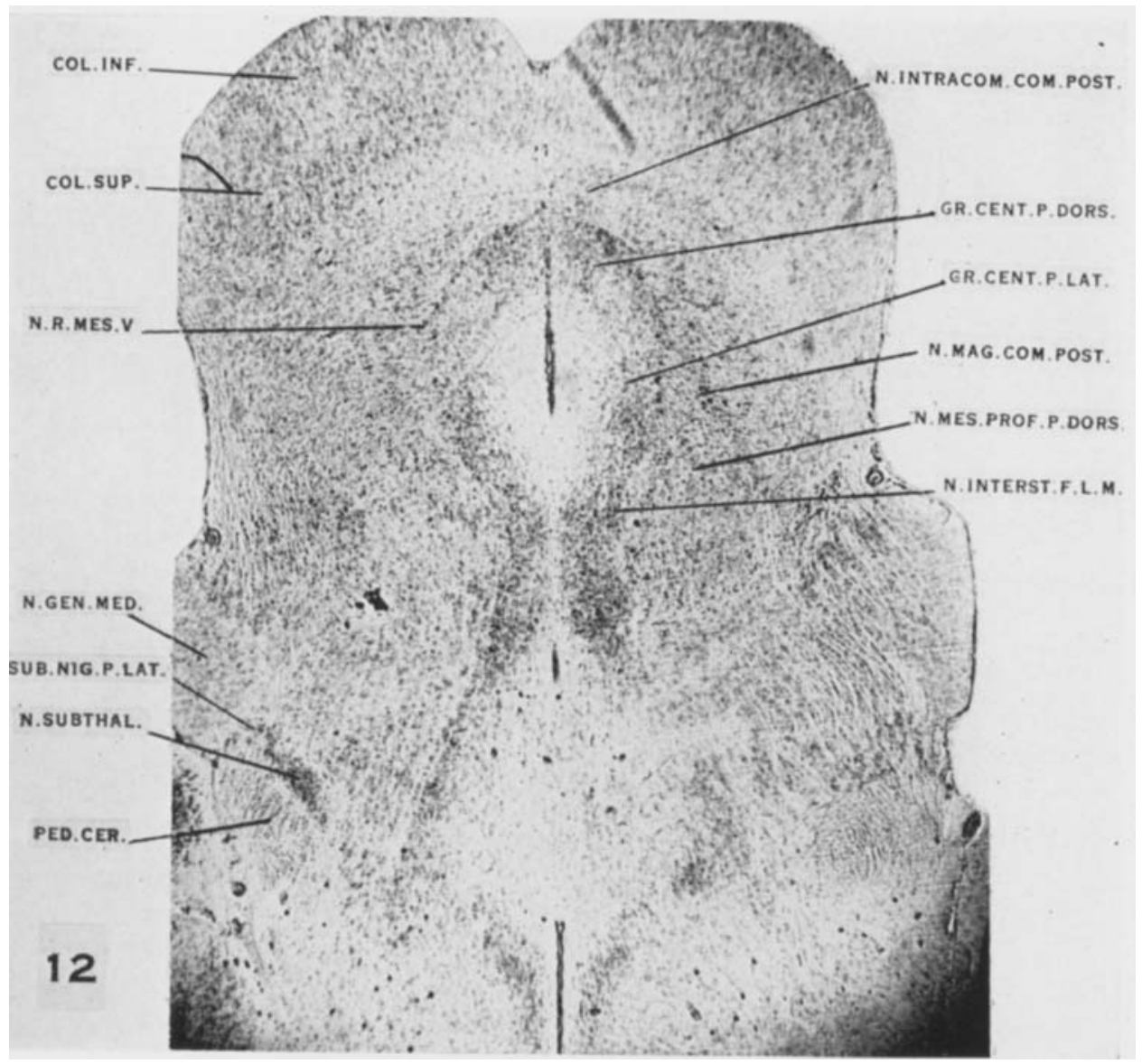


PLATE 8

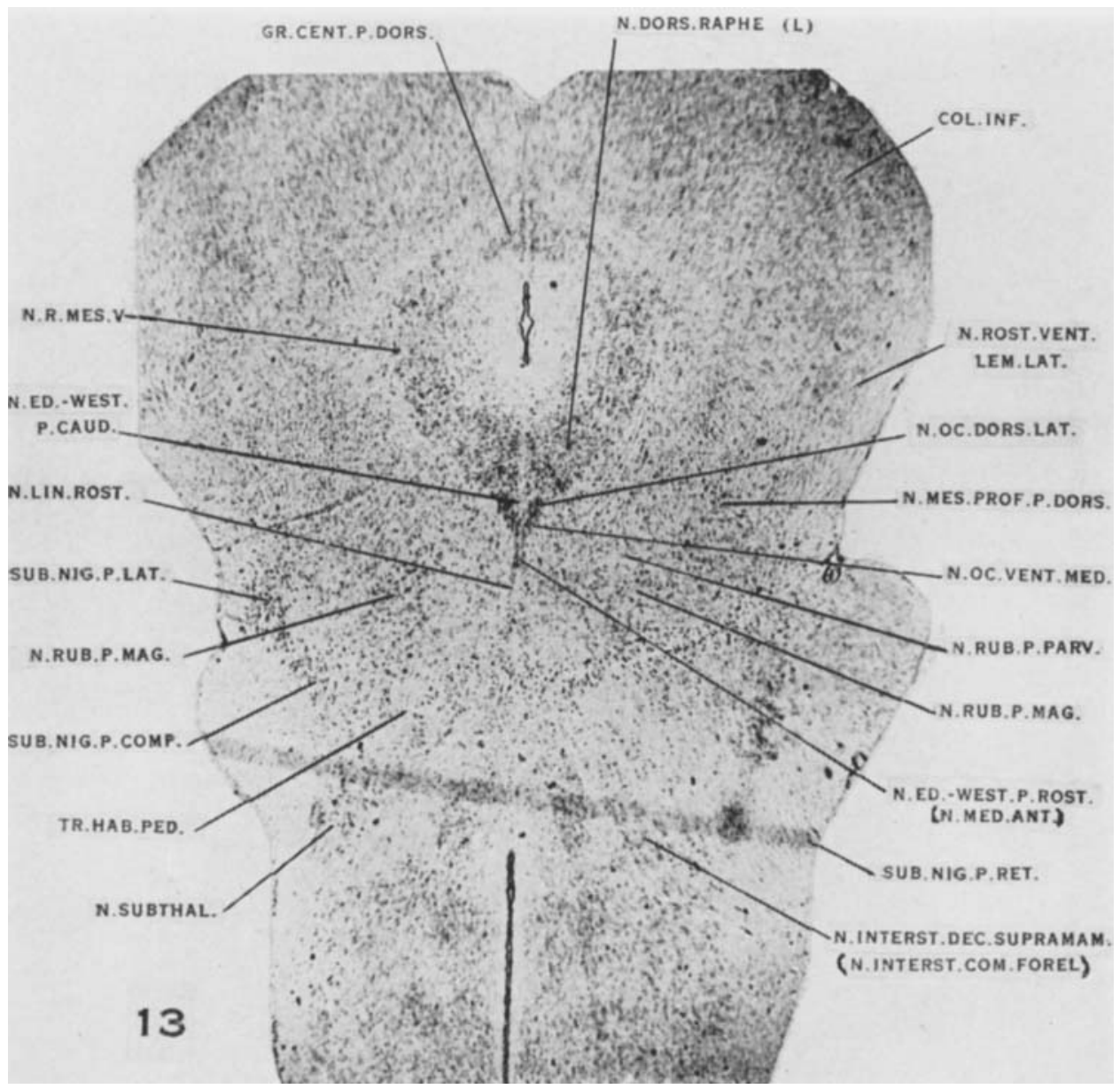




\section{PLATE 9}

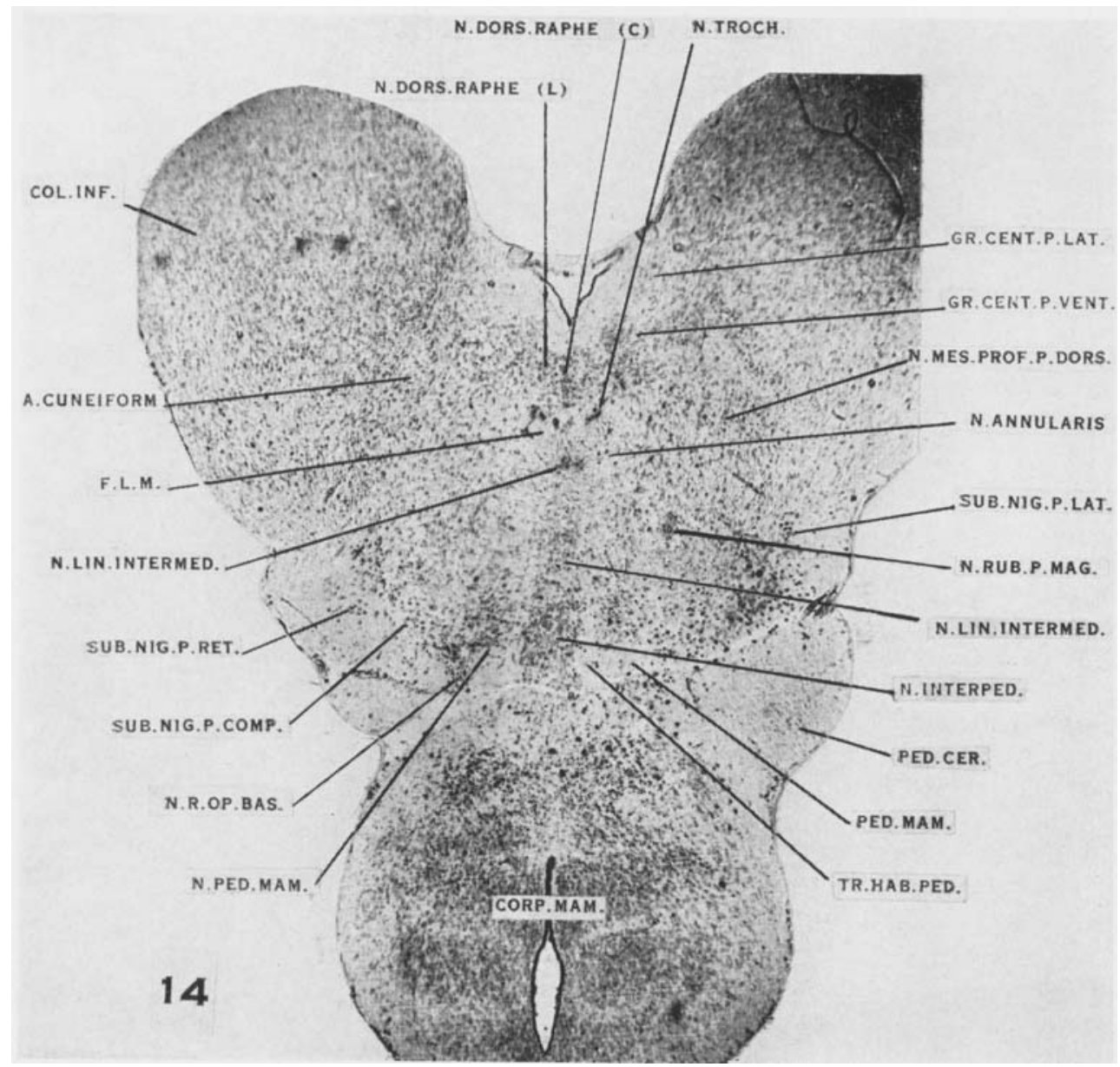


PLATE 10

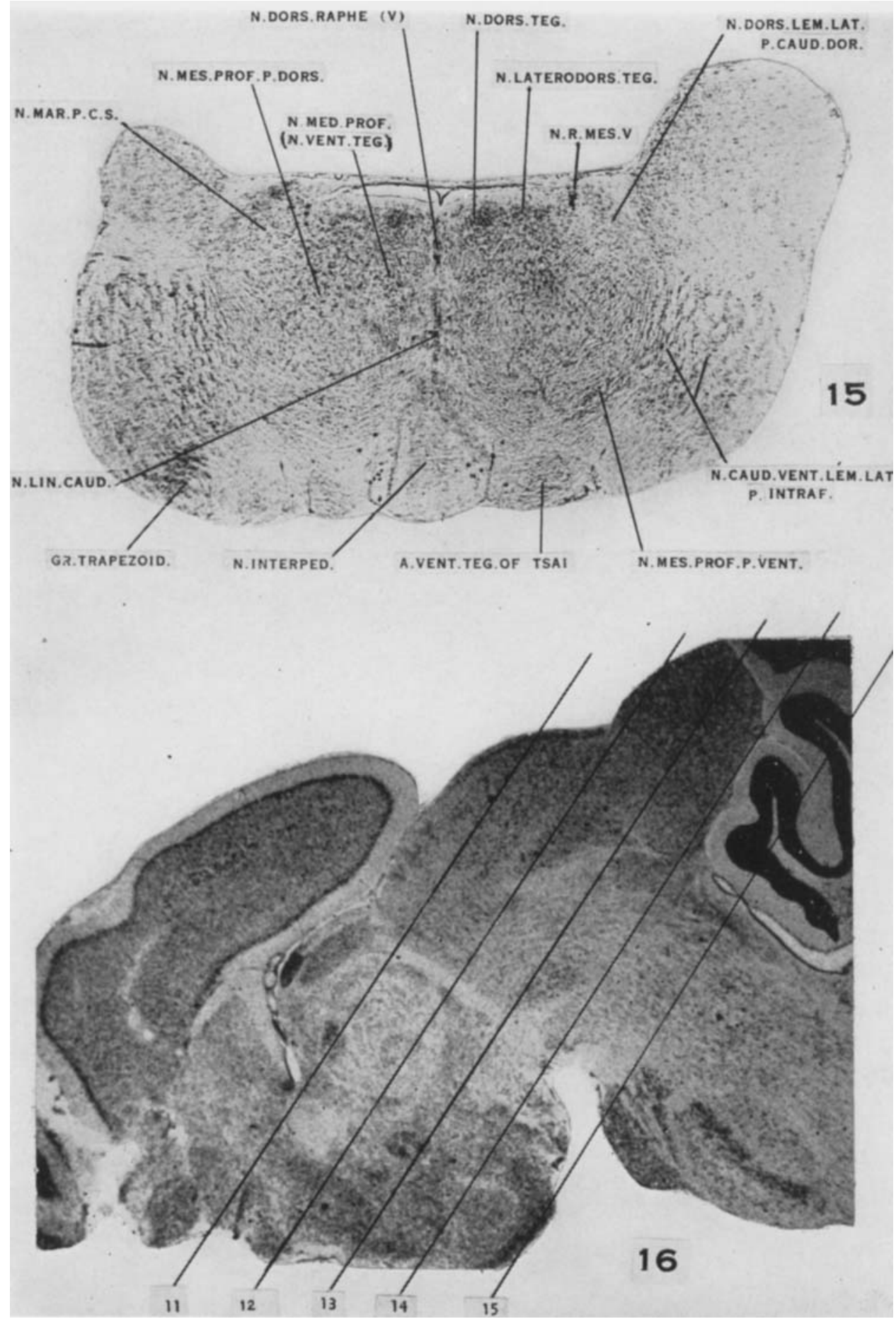

